\title{
IDENTIDADES TERRITORIAIS KALUNGA DA/NA COMUNIDADE QUILOMBOLA DO MIMOSO, EM TOCANTINS
}

\author{
TERRITORIAL KALUNGA IDENTITIES OF/IN THE QUILOMBOLA \\ COMMUNITY OF MIMOSO, IN TOCANTINS
}

Elizeth da Costa Alves ${ }^{1}$

https://orcid.org/0000-0003-1493-0447

http://lattes.cnpq.br/4584041690613816

\section{Augusto Rodrigues da Silva Junior ${ }^{2}$ \\ https://orcid.org/0000-0002-6780-9731 \\ http://lattes.cnpq.br/6208952301327343}

Maria Geralda de Almeida ${ }^{3}$
https://orcid.org/0000-0002-4765-3354
$\underline{\text { htp://lattes.cnpq.br/4465452999284335 }}$

Recebido em: 15 de junho de 2020.

Aprovado em: 20 de julho de 2020.

RESUMO: Nesse artigo objetiva-se discorrer sobre as identidades territoriais Ka-
lunga, da Comunidade Quilombola Rural Mimoso em Tocantins. Amparados pela
geografia cultural, realizamos observações em pesquisas de campo, estudo biblio-
gráfico e análise de narrativas. Utilizamos de metodologias qualitativas e tecemos
reflexões acerca das relações dos Kalunga com o espaço social produzido. Acredi-
tamos que as narrativas orais, advindas da tradição oral e compartilhada entre as

${ }^{1}$ Doutoranda em Geografia Cultural pelo Programa de Pós-graduação em Geografia da Universidade Federal de Goiás, com ingresso em 2016. É mestre em Letras: Literatura e Crítica Literária pela Pontifícia Universidade Católica de Goiás (2011) e especialista em Libras pela Faculdade Futura (2019). Tem graduação em Letras Português/Inglês: e suas respectivas Literaturas pela Universidade Estadual de Goiás (2006) e graduação em Letras Libras (2019), pela Universidade Federal de Goiás. Atualmente é professora efetiva de Língua Portuguesa e Língua Brasileira de Sinais (Libras), no Instituto Federal do Tocantins, em Colinas - TO. E-mail: elizethcosta314@gmail.com.

${ }^{2}$ É poeta, ensaísta, professor Associado de Literatura Brasileira da Universidade de Brasília e coordenador da Cátedra Agostinho da Silva (UnB). Cursa pós-doutorado em Literatura no programa de Pós-Graduação em Língua e Literatura Alemã pela Universidade de São Paulo (FFLCH/USP), com projeto intitulado "Geopoesia e Literatura de Campo centroestina: etnoflâneries por Goiás e Brasília". É pós-doutor pela Universidade do Minho - Departamento de Estudos Portugueses e Lusófonos - Braga/Portugal. Doutor em Literatura Comparada pela Universidade Federal Fluminense (2008). Mestre e graduado em Literatura pela Universidade Federal de Goiás (UFG/1996-2002). E-mail: augustorodriguesdr@gmail.com.

3 Possui graduação em Geografia pela Universidade Federal de Minas Gerais, mestrado e doutorado em Geografia pela Université de Bordeaux III, pós doutorado em Geografia Humana pela Universidad de Barcelona, em Geografia Cultural pela Université Laval, Università Degli Studi Di Genova e Université de Paris IV Paris-Sorbonne. Foi presidente da Associação Nacional de Pós graduação e Pesquisa em Geografia (ANPEGE) de 2009 a 2011. Atualmente é professora colaboradora da Universidade Federal de Sergipe, também é integrante do Programa de Docente Voluntária da Universidade Federal de Goiás, onde é pesquisadora do Laboratório de Estudos e Pesquisas das Dinâmicas Territoriais-LABOTER. Também é pesquisadora junto ao CNPq, com o Grupo de Pesquisa em Geografia Cultural: territórios e identidade. E-mail: mgdealmeida10@gmail.com. 
gerações por meio da memória, formam o vínculo temporal com o passado e com o local onde os sujeitos Kalunga vivem. Portanto, entendemos que os aspectos imateriais, com base nas narrativas orais, são elementos relevantes para a configuração das identidades territorial, da comunidade em questão.

Palavras-chave: Populações Tradicionais. Geografia Cultural. Território. Tradição oral. Cultura.

ABSTRACT: This article aims to discuss the Kalunga territorial identities of the Quilombo Rural Mimoso Community in Tocantins. Base on cultural geography, we carried out observations in field research, bibliographic study and narrative analysis. We use qualitative methodologies and analyze the Kalunga's relations with the produced social space. We believe that oral narratives, derived from oral tradition and shared between generations through memory, form the temporal link between the past and the place where Kalunga subjects live. Therefore, we understand that immaterial aspects, based on oral narratives, are relevant elements for the configuration of territorial identities, in this community.

Keywords: Traditional Populations. Cultural Geography. Territory. Oral tradition. Culture.

\section{INTRODUÇÃO}

Esse artigo tem como tema central questões relacionadas às identidades territoriais do povo Kalunga, da Comunidade Rural Mimoso em Tocantins. Essa comunidade compõe parte do território de remanescentes de quilombos do Norte do Estado de Goiás e Sudeste do Estado do Tocantins.

Com o período da mineração e a formação da cidade de Arraias, no estado do Tocantins, surgem as comunidades quilombolas rurais Lagoa da Pedra e Kalunga do Mimoso. Antes da divisão do estado do Tocantins e Goiás, Mimoso fazia parte dos grupos familiares da comunidade Kalunga de Cavalcante, e por isso eram chamados de Kalungueiros.

Araújo \& Foschiera (2012), alegam que devido a criação do estado do Tocantins (1988), a parte da comunidade pertencente aos municípios de Arraias e Paranã, ficou fora do processo de reconhecimento, desenvolvido pela associação de moradores Kalunga, em parceria com o estado de Goiás, Organizações não Governamentais e as prefeituras dos municípios de Monte Alegre, Cavalcante e Teresina.

Cabe destacar que, mesmo estando em territórios administrativos distintos, os Kalunga têm a mesma ascendência. Os limites geográficos que delimitam os estados não alteraram os vínculos ou o sentimento de pertencimento desses grupos sociais, posto que comungam das mesmas práticas sociais, simbólicas e culturais. Alguns questionamentos propiciaram o desenvolvimento do texto, a saber: de que forma ocorre a apropriação do espaço na comunidade de Mimoso pelas práticas sociais, culturais e simbólicas? Como esses aspectos contribuem para a construção da identidade territorial dos quilombolas? Qual a contribuição das narrativas orais para a compreensão da construção do território e da identidade territorial em Mimoso?

As reflexões são subsidiadas pelo arcabouço teórico e metodológico da Geografia Cultural, uma vez que busca entender o mundo por meio "das relações das pessoas com a natureza, do seu comportamento geográfico bem como dos seus sentimentos e idéias a respeito do espaço 
e do lugar.” (TUAN, 1982, p. 143).

Além disso, como é colocado por Holzer (2008), na Geografia Humanista, 'Espaço, Território e Lugar' podem ser estudadas a partir dos fenômenos humanos, sociais, simbólicos e culturais que envolvem a produção do espaço. O autor também comunga da colocação de Ratzel (1990) de que a descrição dos fenômenos observados e narrados pode contribuir para a compreensão da geografia do homem e sua visão de mundo.

Ademais, contribuições de estudos embasados em outras correntes teóricas e metodológicas são importantes para a construção de uma base conceitual sólida para o desenvolvimento das discussões. Pretende-se com isso, trazer à discussão outras fontes além daquelas de base humanistas. Com isso, aquilo que Duncan (2000) alerta para heterotopia epistemológica, os métodos e correntes teóricas se combinam ou aparecem justapostos, com o intuito de contribuir com reflexões críticas acerca do tema estudado.

O estudo bibliográfico acerca do território, e da identidade territorial, aliado com a metodologia de análise das narrativas orais permitirão o desenvolvimento de reflexões acerca da constituição do território e da identidade Kalunga da Comunidade Mimoso, Tocantins. A hipótese acerca da identidade territorial nessa comunidade se fortalecerá com base nas narrativas orais apresentadas pelos sujeitos de pesquisa, possibilitando correlacionar aspectos geográficos, históricos e culturais, no processo de construção do conhecimento sobre o tema estudado.

\section{O TERRITÓRIO KALUNGA EM TOCANTINS}

As observações realizadas na Comunidade de Mimoso no Tocantins possibilitam reflexões acerca da construção da identidade territorial do povo Kalunga, principalmente aquelas associadas as narrativas orais apresentadas pelos sujeitos de pesquisa. As análises partem, em um primeiro momento, da construção do conceito de território e como se desdobra para a sua relação com a identidade e memória.

Na Geografia, o conceito de território tem início com o geógrafo alemão Friederich Ratzel, nas obras Antropogeografia (1882) e Geografia Política (1897). O autor relaciona o conceito de território ao de solo, e desse modo acaba "coisificando-o". Nas palavras de Souza (2013, p. 93, grifos do autor):

Ratzel esclarece que o Estado não é um "organismo vivo" meramente porque ele "representa uma união do povo vivo com o solo imóvel", mas também "porque essa união se consolida tão intensamente através de interação que ambos se tornam um só." [...] o autor registra que "exclusivamente o solo dá coerência material a um Estado", sendo o solo "tanto o fundamento coerente do Estado quanto o único testemunho palpável e indestrutível de sua unidade."

Assim, o território era compreendido como expressão legal e moral do Estado, refletido na conjunção do solo e do povo, e estabelecido nas relações de poder. Por volta da década de 1970, surgiram as novas concepç̃oes de território na Geografia, principalmente, devido às transformações sociais que aconteceram no mundo, e que mudaram a dinâmica socioespacial. Cavalcanti (2011, p. 198) certifica que a partir de então, o território passa a ser compreendido "em sua multidimensionalidade (ou seja, nas suas dimensões política, econômica, cultural, funcional, simbólica), expressando os fluxos e redes materiais e imateriais das relações sociais."

Representando essa nova fase, tem-se Claude Raffestin, com a obra Por uma Geografia do 
Poder, que argumenta sobre a produção do território. De acordo com Raffestin (1998), o território é produzido a partir do espaço e pelas relações de poder que o envolve. Nas palavras do autor (1998, p. 153) "falar de território é fazer uma referência implícita a noção de limite que, mesmo não sendo traçado, [...], exprime a relação que um grupo mantém com uma porção do espaço". Do Estado ao indivíduo encontram-se atores que produzem o território.

Partindo dessa referência, Souza (2013 p. 78) afirma que o território "é um espaço definido e delimitado por e a partir de relações de poder". Além dessa dimensão, ele aborda outro aspecto mais sutil, na sua visão, sobre os territórios: eles são "antes relações sociais projetadas no espaço que espaços concretos”. Essa ideia é relevante para se pensar as questões relativas às dinâmicas sociais, simbólicas e culturais na construção do território.

Sobre isso, é importante analisar as proposições postas por Haesbaert (2010) em que os aspectos imateriais do território são valorizados. Para o autor, essa categoria pode ser interpretada também pelo viés cultural, quando o território é estudado a partir de uma perspectiva subjetiva, realizada pela apropriação de um grupo social em relação ao espaço vivido, suas práticas sociais e culturais.

Tendo em vista as características de produção do território, que transcendem a perspectiva política e administrativa, as dimensões simbólicas e culturais são perspectivas para se pensar a valorização e apropriação do espaço por um grupo social. Por conseguinte, compreende-se a categoria território em sua acepção ideológica, simbólica e cultural. Cavalcanti (2011, p. 419) explica que o conceito de território em uma abordagem humanista refere-se aos seus "dispositivos simbólicos do poder que regem as relações sociais e configuram os territórios”; e na abordagem histórico crítica como "produto social, numa complexa combinação das horizontalidades e verticalidades, das práticas objetivas e subjetivas".

Ao partir destas premissas, percebe-se que a produção territorial não está vinculada apenas à delimitação política, mas também ao que concerne o "pertencimento" e a "vivência" do atores que projetam seu trabalho, suas práticas sociais e culturais em um determinado espaço. Assim sendo, depreende-se que os territórios formados pelas comunidades remanescentes de quilombos, também são produzidos a partir dos referenciais de vida carregados por aspectos simbólicos e culturais, como os valores, saberes e ações de sociabilidade e solidariedade, além daqueles que conformam questões de delimitação, política e ideológica.

Sobre a comunidade quilombola Kalunga do Mimoso é válido destacar que está localizada a $120 \mathrm{~km}$ do município de Arraias, é formada por 9 núcleos (ocupando os municípios de Arraias e Paranã - TO) divididos em 4 povoados: Mimoso - sede da comunidade, Matas, Aparecida e Albino (Mapa1). É composta por uma média de 250 famílias ${ }^{4}$.

${ }^{4}$ Dados levantados durante a pesquisa de campo de doutorado 2016 - 2018, realizado no IESA/UFG. 
Mapa 1 - Comunidade Kalunga do Mimoso - TO

\section{Comunidade Quilombola Kalunga do Mimoso - TO}
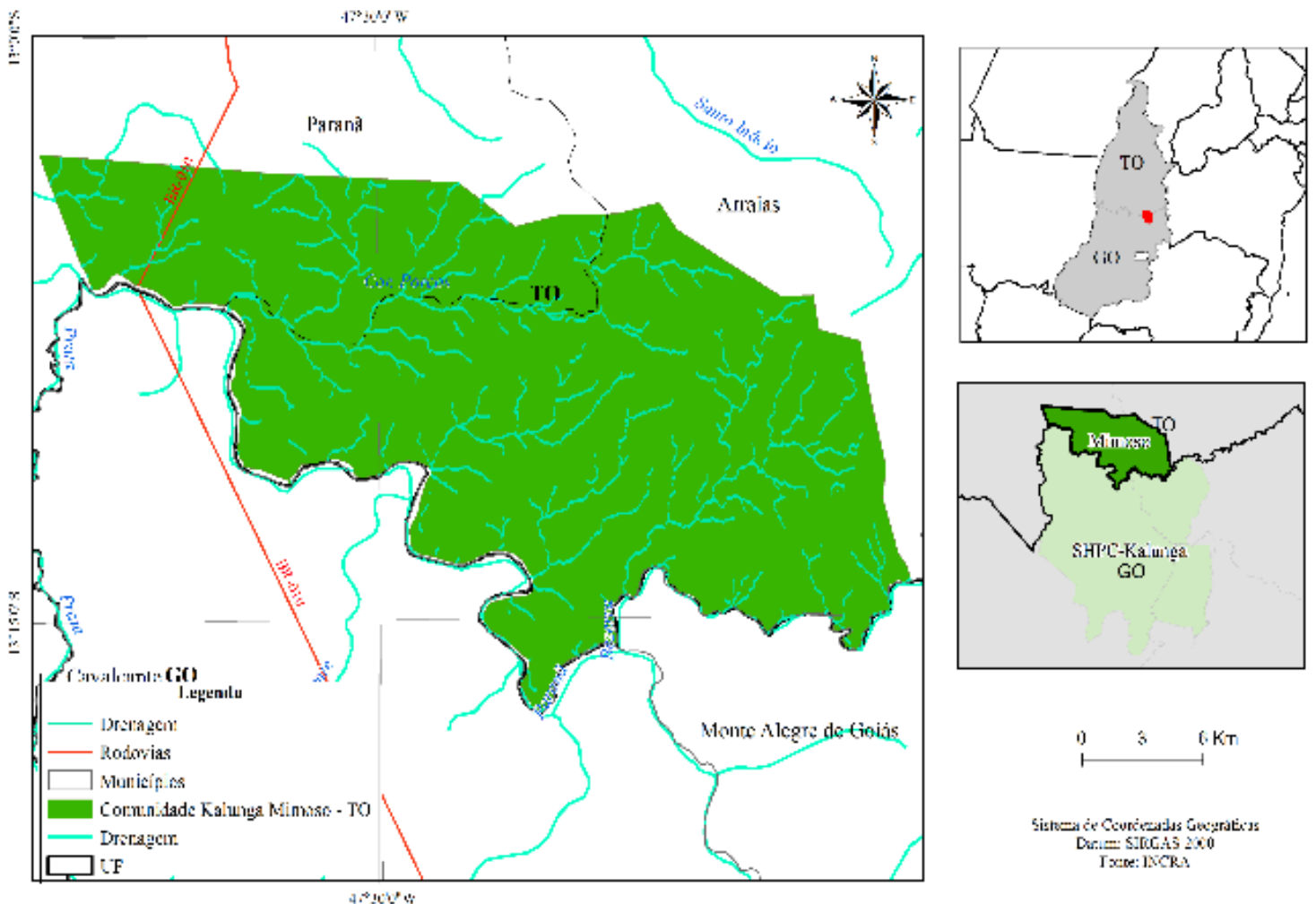

Elaborado por Elizeth da Costa Alves e Sara Alves dos Santos (2020).

Em ocasião do processo de regularização e titulação da porção goiana do território Kalunga, e dos benefícios e investimentos de recursos públicos federais, estaduais, municipais a ele destinados para a promoção da cidadania e do desenvolvimento social criou-se uma situação de injustiça e desigualdade entre indivíduos pertencentes a um mesmo povo e a um mesmo território (OLIVEIRA, 2006 Apud ARAÚJO \& FOSCHIERA, 2012).

O reconhecimento do território pertencente ao Tocantins, como comunidade remanescente de quilombo só veio em 2005, 17 anos após o título dado a parte goiana. A partir daí, Mimoso passa a levar o nome Kalunga do Mimoso. Apesar do reconhecimento, quase nada mudou na vida das pessoas que vivem na região; e a precariedade de serviços básicos como saneamento, moradia e educação ainda é uma realidade na comunidade. De fato, além desses fatores, outros impedem a apropriação política e econômica do território pelos Kalunga, como a questão de titularidade e posse das terras ocupadas pelos quilombolas.

Embora, exista uma relação histórica desses sujeitos com o espaço social produzido por eles e as garantias de posse pelas leis federais, a ação de fazendeiros da região e das autoridades locais se apropriam do território, reforçando a situação de violência contra os direitos e as condições de existência do povo Kalunga. Dessa maneira, apesar da titulação e posse garantida por leis federais, os sujeitos não exercem o "poder" no território que habitam.

Não é raro, ocasiões em que grileiros tem registros de posse da terra, enquanto o Kalunga ocupa o espaço de empregado nas terras que lhe pertencem como direito. Situações como essas evidenciam a apropriação simbólica do território pelos quilombolas, uma vez que a ne- 
gligência dos direitos pela terra não rompem com a ligação e o pertencimento dos sujeitos ao território.

Outro fenômeno que marcou a dinâmica da apropriação do território e as práticas socioculturais dos quilombolas foi a divisão dos dois estados, Goiás e Tocantins. Os grupos sociais denominados Kalunga que ocupam essa região, apesar de separados em territórios específicos (norte de Goiás e sudeste do Tocantins) não sofreram a ruptura com os aspectos simbólicos e culturais, já que a comunidade de Mimoso compartilha com as demais comunidades quilombolas daquela região.

Além disso, elementos ligados a sociabilidade e solidariedade entre os sujeitos quilombolas, e deles com o espaço onde reproduzem suas práticas sociais, econômicas, ideológicas e culturais permitem a construção de uma identidade com o território que é marcado por luta e uma historia de resistência para a sobrevivência e produção cultural, uma vez que possuem o direito à terra, mas em alguns casos não exercem o poder político e econômico sobre ela.

Observa-se que a Comunidade Mimoso, assim como as comunidades quilombolas da região do norte goiano, carregam em suas práticas socioespaciais o reconhecimento e sentimento de pertença ao espaço construído por eles, como as atividades rurais, sociais e culturais, que além de lhe garantirem a sobrevivência permitem os laços com a terra e com a sociedade.

\section{IDENTIDADES TERRITORIAIS DO/NO KALUNGA DO MIMOSO}

A identidade é um conceito que tem sido abordado pelos estudos da Geografia, principalmente em pesquisas cujo arcabouço teórico e metodológico versa pelo paradigma humanista e cultural. Com base na nova abordagem da Geografia Cultural, que surge a partir da década de 1980 na França, propõe-se novos temas para os estudos da Geografia, entre eles, Claval (1997) coloca a apreensão da construção de identidades.

Berdoulay e Entrikin (2012) abordam sobre o assunto e ressaltam os laços entre o sujeito e o seu mundo. Asseguram que o fenômeno da identidade espacial ou territorial pode ser composta de vários elementos sociais. Pode ainda variar entre identidade "relativamente fraca", ou a um "sentimento intenso de pertencimento", que estabelece um vínculo entre o espaço e o grupo. Por conseguinte, os autores afirmam,

o desejo de pertencimento do indivíduo ao grupo e do grupo ao meio pode ser compreendido como um processo essencialmente subjetivo, que está ligado à questão da identidade; quem sou eu? Essa subjetividade não chega, entretanto, a retirar de uma problemática social a questão da identidade, no sentido de que sua resposta implica o sentimento de pertencer a uma comunidade de memória. Smith define a identidade cultural coletiva como "esses sentimentos e valores" ligados a um sentido da continuidade, da memória e da comunidade de destino, no seio de um grupo que compartilhou experiências comuns e possui características culturais comuns (BERDOULAY; ENTRIKIN, 2012, p. 107).

A constituição da identidade coletiva ou individual sempre é um processo contínuo e sofre influências, seja do meio social, cultural, da historicidade, ou até de questões espaciais e de tempo. Há uma apropriação simbólico-afetiva nesse processo; e no pensamento de Cruz (2007, p. 16) os vínculos de pertencimento e de identificação que caracterizam a identidade, são constituídos pelas tradições ("raízes", heranças, passado, memórias etc.) e pelas traduções (estratégias para o futuro, "rotas", "rumos", projetos, etc.). 
Nesse mesmo sentindo, Giddens afirma que a tradição colabora para o processo de formação da identidade individual ou coletiva. Ela garante a "manutenção" e "conexão" entre "identidade pessoal" e "identidades sociais", primando pela "segurança ontológica", ou seja, pela ordem e continuidade a respeito das experiências do indivíduo. Nas palavras do autor:

[...] a tradição é um meio de identidade. Seja pessoal ou coletiva, a identidade pressupõe significado; mas também pressupõe o processo constante de recapitulação constante e reinteração observado anteriormente. A identidade é a criação da constância através do tempo, da verdadeira união do passado com um futuro antecipado. Em todas as sociedades, a manutenção da identidade pessoal, e sua conexão com identidades sociais mais amplas, é um requisito primordial de segurança ontológica (GIDDENS, 2012, p. 125).

Tendo em vista, que a memória coletiva e as tradições contribuem para a formatação da identidade cultural, a escolha pelas narrativas orais como uma das metodologias se justifica para o desenvolvimento do texto, uma vez que advindas da tradição oral, contribuem para a construção da identidade Kalunga, no território quilombola Kalunga do Mimoso, em Tocantins. A partir das narrativas orais é possível identificar elementos que presumem a relação entre a identidade e o território.

De acordo com Haesbaert (1999, p. 180), a identidade territorial "recorre a uma dimensão histórica, do imaginário social, de modo que o espaço que serve de referência condense a memória do grupo". Assim sendo, os Kalunga comungam dos mesmos hábitos, valores e costumes, historicamente construídos, e que somam-se aos aspectos que caracterizam o território apropriado e produzido por eles.

Sobre essas referências que promovem construção da identidade territorial, Cruz (2007, p. 25-26) alerta para os elementos fundamentais para que isso ocorra: o espaço de referência identitária; "e a consciência de pertença e do auto reconhecimento". Assim sendo, o fato de identificarem com os aspectos simbólicos e culturais daquele território em específico, tendo como base as dinâmicas socioespaciais, permite para a construção da ideia de identidade vinculado ao território em que vivem.

Em síntese, a identidade territorial está ligada à memória social do grupo e sua construção histórica de relação de pertencimento com um dado território. $\mathrm{O}$ auto reconhecimento daquele território, em todo o seu processo de construção dos aspectos importantes para as suas singularidades, pelos sujeitos permite a compreensão do fenômeno da identidade territorial, a partir dos fenômenos descritos que desvelam-se em narrativas essencialmente geográficas (LA BLACHE, 1985). Um dos sujeitos entrevistados, em suas narrativas observa sua relação com o território, o qual não exerce nenhum poder, mas estabelece um vínculo essencial: da sobrevivência. Esse aspecto reflete a apropriação simbólica de pertencimento do quilombola e o território que ocupa.

Meus pais morreram e deixaram eu e meus irmãos muito criança. Fui criado jogado, por um e por outro. Sempre maltratado, apanhava e trabalhava demais, para ter o que comer. Enquanto

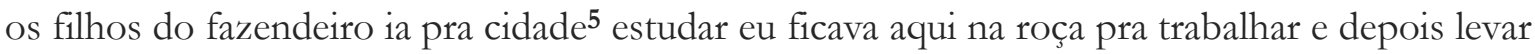
as coisas pra eles, todo mês, montado a cavalo com cargueiro nas costas. Não tinha nem roupa pra vestir, me lembro que quando chegava gente na casa eu corria pro mato pra não me verem

5 Arraias - TO.

PRACS: Revista Eletrônica de Humanidades do Curso de Ciências Sociais da UNIFAP https://periodicos.unifap.br/index.php/pracs ISSN 1984-4352 Macapá, v. 13, n. 2, p. 121-130, jul./dez. 2020 
pelado. As terras que meus pais tinham por aqui foram tomadas pelos fazendeiros da época e vendidas pra outras pessoas de fora. Hoje eu não tenho nenhum pedaço aqui. Estou esperando o Incra indenizar os fazendeiros que faltam, pra poder pegar um lugarzinho pra mim (E. A. M., 62 anos).

Ademais, as relações culturais e as dinâmicas socioespaciais imprimem no território a identidade do grupo, bem como o sentido de pertencimento para os sujeitos. O território, portanto, é resultado também de um processo de relação que se instaura entre comunidade e o espaço do qual se apropria ou produz um mecanismo para reprodução da vida, do trabalho e sua cultura.

Enfim, sabe-se que a identidade e o território estão imbricados, pois a dimensão espacial os envolve; e a identidade necessita de elementos como, a cultura, o espaço, o tempo, a crença, sem os quais não poderia ter uma definição. "O sentimento identitário permite que se sinta plenamente membro de um grupo, dotá-lo de uma base espacial ancorada na realidade" (CLAVAL, 1999, p. 16).

Associada a essas questões, a memória surge como elemento importante para reforçar o sentimento de pertencimento ao território, como fatos que rememoram questões relativas a produção do espaço: narrativas sobre as origens quilombolas, o trabalho rural, a escassez no cerrado, as dinâmicas de sociabilidade e solidariedade entre os moradores e as práticas ligadas a cultura afro-brasileira.

Cavalcanti (2011, p. 419) analisa que "a forte carga de relação entre os sujeitos e a constituição do território leva alguns atores a fazerem sua ligação estreita com o processo de construção da identidade". Sobre isso, um dos moradores explica as crenças Kalunga e como isso tornou-se aspecto identitário no processo de construção simbólica do território:

Aqui é o seguinte, esse rio por exemplo, a mão corta dum tipo e o outro de outro. Então deu esse nome de Kalunga quando eu cheguei por aqui, ele não é Kalunga, então, tem um corgo lá em cima no Riachão, que chama Kalunga. Aí, como lá chama Kalunga, ajeitou essa área, é uma área do Kalunga. E por Kalunga ficou. Assim que eu vejo eles contando. Tem o corgo, pra cá de Procopa ${ }^{6}$, tem o corgo por nome Kalunga. Aí dividiu, diz assim, vai ser Kalunga, então ficou geral, ai então é Kalunga tudo, mas Kalunga é o corgo lá. Nascido lá, e encavado no Paranã (R.F.S., 70 anos).

O narrador fala que o nome da comunidade surgiu por conta de um pequeno rio que está localizado no Kalunga de Goiás - no município de Monte Alegre, bem perto da casa de Dona Procópia. Ao contarem fatos históricos ligados à construção e produção territorial, os sujeitos Kalunga, reforçam a cultura, as práticas sociais, os costumes e os valores de seu povo. Esses, construídos por meio das dinâmicas de sociabilidade estabelecidas por eles.

Ademais, o fato de reconhecimento e pertencimento ao território ligado à sua forma de construção permite refletir acerca das referências que esses sujeitos tem sobre a sua identidade e como isso influenciou na reprodução do espaço social.

${ }^{6}$ Matriarca da Comunidade Quilombola Kalunga de Monte Alegre - Sítio Histórico do Kalunga de Goiás. 


\section{PARA NÃO CONCLUIR}

Verifica-se que a identidade territorial na comunidade Kalunga Mimoso tem como uma de suas características o vínculo e o sentimento de pertencimento com o espaço vivido, apesar de situações que impedem o sujeito exercer o poder sobre a terra, como mecanismos que inviabilizam a titularidade e posse.

Além disso, o direito garantido em lei, mesmo que muitas vezes negligenciado, não é o responsável por construir as ideias de pertencimento ao território. Como observado, as práticas ligadas aos costumes e valores, bem como a apropriação do território para a reprodução da vida, são os aspectos que contribuem para a construção da identidade.

Uma das metodologias que permite identificar a formação desses vínculos com o espaço é a tradição oral, que tem na memória coletiva e compartilhada entre as gerações uma importante ferramenta para analisar o vínculo com o espaço a partir da relação temporal com o passado e com o local onde vivem. Portanto, o relato oral é fundamental para entender as noções de identidade estabelecida entre os habitantes, quando descrevem e narram fatos históricos e geográficos que contribuíram para a formação do grupo social que ocupam aquele território.

Essas identidades são integrantes do imaginário social e apresentam-se mediadas por discursos firmados em elementos positivos, orientando os indivíduos quanto ao seu pertencimento de grupo e o seu território, e aos fenômenos que os sujeitos relatam como importantes para a construção e sobrevivência da sociedade.

Assim, com as histórias que são contadas no território quilombola Kalunga do Mimoso TO, pode-se levantar questões responsáveis por transmitir visões de mundo, experiências de vida, ideologias e especificidades traduzidas numa linguagem simbólica. E por intermédio dessa linguagem revelam-se verdades, crenças, vontades e possibilitam a compreensão do outro e sua identidade mediada pelo território que ocupam.

Desse modo, constata-se a importância do sentimento de pertença e práticas sociais como elemento indispensável para a promoção da identidade territorial baseada na participação coletiva dos sujeitos partícipes no processo de produção do território, de onde, muitas vezes não exercem o poder, mas o produzem cotidianamente, por meio do trabalho e de outras relações socioespaciais.

\section{REFERÊNCIAS}

ARAUJO, Sandra Regina Evangelista; FOSCHIERA, Atamis Antonio. As contradições entre a realidade socioeconômica da comunidade quilombola Mimoso do Kalunga e a garantia dos direitos legais de educação e território. Revista Pegada. v. 13, n. 2, 2012.

BERDOULAY, V; ENTRIKIN, N. lugar e sujeito, perspectivas teóricas. In: HOLZER, H. et al (orgs.). Qual o espaço do lugar? São Paulo: Perspectiva, 2012. p. 93-116.

CLAVAL, Paul. O território na transição da pós-modernidade. Geographia, 1, (2). 1999. p. 7-26.

CAVALCANTI, L. de S. Ensinar geografia para a autonomia do pensamento. Revista da Anpege, V. 7, n. 1 (edição especial), 2011. p. 193-203.

COSGROVE, D. E. Em direção a uma geografia cultural radical: problemas da teoria. Tradução: Olívia B. Lima da Silva de "Towards a Radical Cultural Geography of Theory" In: Antípode - a Radical Journal of Geography, Worcester, 15 (1). 1983. p. 1-11. 
CRUZ, V. C. Itinerários teóricos sobre a relação entre território e identidade. In: BEZERRA, A. C. A. et. Al. (Orgs.). Itinerários Geográficos. Niterói. EdUFF, 2007. p. 13-35.

DUNCAN, James S. Após a guerra civil - reconstruindo a geografia cultural como heterotopia. CORRÊEA, Roberto Lobato; ROSENDAHL, Zeny (Orgs.). Geografia Cultural: um século (2). Rio de Janeiro: EdUERJ, 2000.

GIDDENS, Anthony. A vida em uma sociedade pós-tradicional. In: GIDDENS, A; LASH, S; BECK, U (orgs.). Modernização reflexiva: política, tradição e estética na ordem social moderna. São Paulo: EdUNESP, 2012. p. 89-166.

HAESBAERT, Rogério. O mito da desterritorialização: do fim dos territórios à multiterritorialidade. Rio de Janeiro: Bertrand Brasil, 2010.

Identidades territoriais. In ROSENDAHL, Zeny; CORRÊA, Roberto Lobato (Orgs).

Manifestações da Cultura no Espaço. Rio de Janeiro: EdUERJ, 1999.

HOLZER, Werther. A geografia humanista: uma revisão. Espaço e Cultura. Edição Comemorativa, p. 137-147, 1993-2008.

BLACHE, Vidal de La. As características próprias da geografia. In CHRISTOFOLETTI, A. (Org.). Perspectiva da geografia. 2. Ed. São Paulo: Difel, 1985.

MORAES, A. C. R. Geografia, interdiciplinaridade e metodologia. Mimeografo. s. n. t.

RAFFESTIN, Claude. Por uma Geografia do poder. SP: Ática, 1993. p. 143-163.

RATZEL, F. Geografia do homem (Antropogeografia). In: MORAES, Antonio. C. R. (Org.). Ratzel. São Paulo: Ática, 1990. p. 54-107.

SOUZA, M. L. O território: sobre espaço e poder, autonomia e desenvolvimento. In: CASTRO, Iná Elias de; GOMES, Paulo Cesar da Costa; CORREAA, Roberto Lobato. (Orgs.). Geografia: conceitos e temas. Rio de Janeiro: Bertrand Brasil, 1995.

SOUZA, M. L. de. Território e (des)territorialização. In: _. Os conceitos fundamentais da pesquisa sócio-espacial. Rio de Janeiro: Bertrand Brasil. 2013. p. 77-110.

TUAN, Yi-Fu. A geografia humanística. In: CHRISTOFOLETTI, A. (Org.). Perspectivas da Geografia. São Paulo: Difel, 1982. Cap. 7, p. 143-164. 